\title{
Independance of Glucagon and Insulin Handling by the Isolated Perfused Dog Kidney
}

\author{
P. J. Lefebvre, A. S. Luyckx and A. H. Nizet \\ Institute of Medicine, University of Liège, Liège, Belgium
}

Summary. The effect of raising arterial plasma glucagon concentrations on kidney glucagon uptake was investigated using an isolated dog kidney perfused with whole blood. In addition, the effect of insulin on the magnitude of glucagon uptake by the kidney was studied at various glucagon concentrations. Renal vein plasma glucagon (V) has been found to be proportional to renal artery plasma glucagon (A). V and A were highly significantly correlated. In the absence of exogenous insulin infusion, $V$ equalled $0.733 \pm$ $0.034 \mathrm{~A}$, while in the presence of insulin $\mathrm{V}$ equalled $0.747 \pm 0.015 \mathrm{~A}$. When kidney glucagon uptake was measured directly it increased as a function of arterial plasma glucagon. The calculated regression lines were similar in the presence and in the absence of insulin. The mean clearance rate of glucagon by the kidney was similar at low, medium or high concentrations of glucagon and was not affected by the presence of insulin at a mean concentration of $335.7 \pm 15.7$ $\mu \mathrm{U} / \mathrm{ml}$. At this concentration of insulin, kidney insulin uptake was not affected by glucagon at concentrations ranging from 32 to $1600 \mathrm{pg} / \mathrm{ml}$. Comparison of kidney glucagon uptake at similar arterial plasma glucagon concentrations, but with different renal plasma flows, indicated that kidney glucagon uptake is more dependant on arterial plasma glucagon concentration than on the quantity of glucagon entering the kidney per minute. It is concluded that: 1) kidney glucagon uptake increases as a function of arterial plasma glucagon concentration; 2) the clearance rate of glucagon is similar at low, medium or high arterial concentrations of glucagon; 3) at concentration of $300-350 \mu \mathrm{U} / \mathrm{ml}$, insulin does not affect kidney glucagon uptake, and 4) at concentrations of glucagon up to $1600 \mathrm{pg} / \mathrm{ml}$, renal insulin uptake is not affected by glucagon. These studies indicate that insulin and glucagon are handled independantly by the kidney of the dog.
Key words: Glomerular filtration rate, glucagon, insulin, kidney, metabolism, renal plasma flow.

Previous studies from our Laboratories, using dog kidneys transplanted acutely to the neck vessels of a perfusing anaesthetized dog, have indicated that under basal conditions, the glucagon uptake by the kidney averaged $89 \pm 14 \mathrm{pg} / \mathrm{min} / \mathrm{g}$ of kidney, a value which was significantly reduced to $42 \pm 5 \mathrm{pg} / \mathrm{min} / \mathrm{g}$ after massive intravenous glucose load [1]. Contrary to insulin, no correlation was found between arterial glucagon concentration and kidney glucagon uptake; it was suggested that this might be due to the fact that the glucagon concentrations were too low and that the range of arterial glucagon concentrations reached was relatively narrow. In order to overcome these limitations, we performed the present experiments using isolated dog kidneys perfused with whole blood. In the first part of this work, we investigated the effect on renal glucagon uptake of raising arterial plasma glucagon concentrations by exogenous infusion of this hormone. Recent investigations have demonstrated the presence in the kidney and muscle of a glucagon degrading enzyme and it was suggested that the same enzyme might be involved in the degradation of both insulin and glucagon [2-4]. After isolation and purification of this enzyme from rat skeletal muscle, it was demonstrated that insulin served as a competitive inhibitor of glucagon degradation and that glucagon itself was a competitive inhibitor of insulin degradation [2]. In view of the potential physiologic significance of this finding, we investigated, at various glucagon concentrations, the effect of insulin on the magnitude of glucagon uptake by the kidney. This constitutes the second part of the present investigation. 


\section{Material and Methods}

\section{Perfusion of Isolated Dog Kidneys}

Perfusion equipment and basic experimental conditions have been described previously [5,6]. Two identical machines were used for simultaneous separate perfusion of both kidneys of the same animal. After an overnight fast, kidney donor dogs, of both sexes, weighing $10.1 \pm 0.7 \mathrm{~kg}$ (range 8-12) and blood donor dogs, weighing $27.1 \pm 1.2 \mathrm{~kg}$ (range 22-34) were anaesthetized using pentobarbital $(30 \mathrm{mg} / \mathrm{kg} \mathrm{i}$. v.) and were given $25000 \mathrm{I}$. U. heparin intravenously. Blood was obtained from the carotid arteries of the blood donor; approximately $900 \mathrm{ml}$ were collected in about 2 minutes. The blood was mixed by gentle shaking and divided into two equal portions, one for each perfusing machine. Ten per cent Trasylol ${ }^{\circledR}(5000 \mathrm{KI}$ per ml) was added to the blood prior to its introduction in the machines. In preliminary experiments, the effect of Trasylol ${ }^{\circledR}$ on glucagon conservation during perfusion as well as the possible influence of Trasylol ${ }^{\circledR}$ on kidney function was investigated (see section on Results). After careful surgical preparation, both kidneys of the kidney donor dog were isolated and simultaneously transfered to the perfusion machines. The duration of renal ischaemia never exceeded 90 seconds. The experiments were conducted at a temperature of $37^{\circ} \mathrm{C}$; the blood flow of the pump was continually adjusted throughout the experiments in order to hold perfusion pressure at a permanent level of $140 \mathrm{~mm} \mathrm{Hg}$. Transient initial vasoconstriction was minimized by the addition of $25 \mathrm{mg}$ Promethazine (Phenergan Specia ${ }^{\circledR}$ ) to the blood immediately before introducing it into the perfusion equipment.

\section{Infusions}

In all instances, exogenous creatinine was infused in order to measure glomerular filtration rate (GFR): a priming dose of $4.5 \mathrm{ml}$ of a 2 per cent solution of creatinine in Ringer's fluid was added at the beginning and was followed by a continuous infusion at 0.09 $\mathrm{ml} / \mathrm{min}$ of the same solution. In the control experiments, saline supplemented with crystallized bovine albumin ( $1 \mathrm{~g} / 100 \mathrm{ml})$ (Calbiochem, San Diego, Calif.) was infused during 3 consecutive periods of $30 \mathrm{~min}$ each at a rate of $0.01,0.02$ and $0.05 \mathrm{ml} / \mathrm{min}$ respectively. In the glucagon infusion experiments, $60 \mathrm{ng}$ of glucagon (Pork glucagon, lot MC6770, Novo, Copenhagen) in a volume of $1 \mathrm{ml}$ saline supplemented with albumin $(1 \mathrm{~g} / 100 \mathrm{ml})$ was injected at the beginning of the infusion; this was followed by 3 consecutive periods of $30 \mathrm{~min}$ during which a $600 \mathrm{ng} / \mathrm{ml}$ solution of glucagon in saline enriched with albumin
$(1 \mathrm{~g} / 100 \mathrm{ml})$ was infused at a rate of $0.01,0.02$ and $0.05 \mathrm{ml} / \mathrm{min}$, or 6,12 and $30 \mathrm{ng}$ glucagon $/ \mathrm{min}$, respectively. In two additional series, saline infusions or glucagon infusions were associated with insulin infusions: insulin (Actrapid ${ }^{\circledR}$, Novo Copenhagen) was injected at a loading dose of $300 \mathrm{mU}$ in a volume of $1 \mathrm{ml}$ of saline enriched with albumin $(1 \mathrm{~g} / 100 \mathrm{ml})$ followed by a continuous infusion of insulin at a dose of 4 $\mathrm{mU} / \mathrm{min}$ in a volume of $0.05 \mathrm{ml} / \mathrm{min}$ of the same diluent. In some of these experiments, a fourth glucagon infusion period at a rate of $0.1 \mathrm{ml} / \mathrm{min}$ (i. e. 60 $\mathrm{ng} / \mathrm{min}$ ) was performed. All infusions were performed in the renal vein, in order to insure proper mixing prior to return of blood to the kidney.

\section{Collection of Samples}

Urine samples were collected during the last $5 \mathrm{~min}$ of each infusion period and their volume was measured with graduated cylinders. At the beginning, midpoint and end of each urinary collection period, blood was taken simultaneously from the artery and the vein of the perfused kidney by free flow into heparinized tubes, using sidebranched cannulas. Blood flow through the kidney was determined immediately after each sampling by means of a side-branched graduated $25-\mathrm{ml}$ pipette and temporary occlusion of the venous return. Preliminary experiments indicated that satisfactory steady state levels of plasma creatinine, glucagon, and insulin were reached during the determinations of renal and urinary clearances.

\section{Analytical Procedures}

The plasma glucose concentration was determined by an enzymatic procedure [7] and plasma and urinary creatinine levels were measured by the AutoAnalyzer ${ }^{\circledR}$ method. For hormone assays, $0.4 \mathrm{ml}$ of a solution containing Trasylol ${ }^{\circledR} 5000 \mathrm{U} / \mathrm{ml}$ and $\mathrm{Na}_{2} \mathrm{ED}$ TA $12 \mathrm{mg} / \mathrm{ml}$ were added to $3.6 \mathrm{ml}$ of blood. The latter was immediately centrifuged at $+4^{\circ} \mathrm{C}$ and the separated plasma was stored at $-20^{\circ} \mathrm{C}$. Plasma insulin was assayed by radioimmunoassay [8] using an antiporcine insulin antiserum. Human insulin was used as a standard, and all samples from a single experiment were assayed in the same series using the same standard curve. The identity of reactivity of dog and human insulin with regard to the anti-insulin antiserum used was validated by demonstrating the parallelism of the two dilution curves. Plasma insulin was determined in duplicate. Plasma glucagon was determined in duplicate by a classical radioimmunoassay procedure, using ${ }^{131} \mathrm{I}$-pork glucagon as tracer, $30 \mathrm{~K}$ antiserum (kindly provided by Dr. Roger H. Unger, Dallas, Texas), which is considered to be specific for 
glucagon, and dextran-charcoal separation of free from antibody-bound hormone [9]. The haematocrit was determined for each arterial sample.

\section{Calculations}

At the end of each experiment, the kidneys were carefully dissected, decapsulated, washed and weighed. GFR was determined on the basis of creatinine clearances. The glucagon concentrations of the three samples obtained during each collection period were averaged and the mean was used to indicate the ,mean arterial plasma glucagon concentration" of the period under consideration; the "mean venous plasma glucagon concentration" was calculated in the same manner. The mean renal plasma flow was calculated from the measured blood flow and the haematocrit.

The arteriovenous difference in plasma glucagon concentrations multiplied by the renal plasma flow gave the kidney glucagon uptake. The arterial plasma glucagon concentration multiplied by the renal plasma flow gave the quantity of glucagon entering the kidney per minute. The "clearance rate of glucagon by the kidney" was defined as the number of mililiters of plasma cleared of the hormone per minute. It was calculated by dividing the kidney glucagon uptake by the arterial glucagon concentration. All calculations were expressed per gram of kidney. Similar calculations were performed for insulin. The results were analyzed statistically using the Student's $t$ test for paired or non-paired data. Correlation coefficients were calculated according to classical procedures [10].

\section{Results}

\section{Presence of Trasylo ${ }^{\circledR}$ in the Perfusion System}

a) Does Trasylo ${ }^{\circledR}$ Affect Kidney Function? In 3 preliminary experiments, one kidney was perfused with blood supplemented with Trasylol ${ }^{\circledR}(500 \mathrm{U}$ per ml of blood), while the other kidney of the same dog was perfused with blood lacking Trasylol ${ }^{\circledR}$ (the latter was replaced by an appropriate volume of the Trasylol ${ }^{\circledR}$ diluent). Eleven parallel collections were obtained. The results, given in Table 1, show that the mean values of urinary output and renal blood flow were not affected by the presence of Trasylol ${ }^{\circledR}$ while mean GFR was slightly increased. However, paired comparison of the results showed urinary output and GFR to be slightly but significantly increased in the presence of Trasylol ${ }^{\circledR}$, while renal blood flow was not affected.

b) Does Trasylo ${ }^{\circledR}$ Protect Glucagon against Destruction in the Perfusion System? In a preliminary experiment, one kidney of the same donor was perfused with and the other without Trasylol ${ }^{\circledast}$, as described above. Plasma glucagon concentration in the perfusing blood before its addition to the machines was $118 \mathrm{pg} / \mathrm{ml}$. After $30 \mathrm{~min}$ perfusion, glucagon concentration was $111 \pm 14 \mathrm{pg} / \mathrm{ml}$ in the blood containing Trasylol ${ }^{\circledR}$ and $70 \pm 8 \mathrm{pg} / \mathrm{ml}$ in the blood lacking Trasylol ${ }^{\circledR}$. After 90 min perfusion, the respective glucagon plasma concentrations were $124 \pm 3 \mathrm{pg} / \mathrm{ml}$ and $56 \pm 2.5 \mathrm{pg} / \mathrm{ml}$. At these plasma glucagon levels, no significant kidney glucagon uptake, as calculated from the arterio-venous differences in glucagon was recorded.

It was concluded that 1 ), Trasylol ${ }^{\circledR}$ has only slight effects on kidney function and that 2) Trasylol ${ }^{\circledR}$ effectively protects glucagon from degradation in the blood during perfusion. It was therefore decided to use Trasylol ${ }^{\circledR}$ in all subsequent experiments.

\section{Renal Vein Versus Renal Artery Plasma Glucagon Concentration}

Glucagon infusions resulted in arterial plasma glucagon concentrations ranging from 26 to 1184 $\mathrm{pg} / \mathrm{ml}$ and in venous plasma glucagon concentrations ranging from 6 to $800 \mathrm{pg} / \mathrm{ml}$. Renal vein plasma glucagon concentration $(\mathrm{V})$ has been found to be proportional to renal artery plasma glucagon level (A). V and A were highly significantly correlated $(\mathrm{r}=0.987 ; \mathrm{n}=$ $31 ; \mathrm{p}<0.001$ ) with $\mathrm{V}$ being equal to $0.733 \pm 0.034 \mathrm{~A}$. When exogenous insulin was infused, reasonably stable plasma insulin levels were obtained: mean plasma insulin averaged $336 \pm 16 \mu \mathrm{U} / \mathrm{ml}(\mathrm{n}=41)$. In these experiments, when glucagon was perfused with insulin, glucagon infusions resulted in arterial plasma glucagon concentrations ranging from 32 to 1600 $\mathrm{pg} / \mathrm{ml}$ and in venous plasma glucagon concentrations ranging from 26 to $1275 \mathrm{pg} / \mathrm{ml}$. Here again, $\mathrm{V}$ was proportional to $\mathrm{A}, \mathrm{V}$ and $\mathrm{A}$ were highly significantly correlated $(\mathrm{r}=0.980 ; \mathrm{n}=39 ; \mathrm{p}<0.001)$ and $\mathrm{V}$ equalled $0.747 \pm 0.015 \mathrm{~A}$. No systematic change in renal plasma flow was observed in both experimental conditions Thus, the above-mentioned calculations indicate that, at any glucagon concentration investigated, an average of $25 \%$ of glucagon in the arterial blood is taken up by the kidney. This value was not affected by the presence of insulin.

\section{Measured Kidney Glucagon Uptake as a Function of Arterial Plasma Glucagon. Effect of Insulin}

As shown in Figure 1, kidney glucagon uptake increased as a function of arterial plasma glucagon $(r=$ $0.940 ; p<0.01$ ). Since blood flow was not systematically modified, a similar correlation existed between kidney glucagon uptake and the quantity of glucagon 
Table 1. Effect of Trasylol ${ }^{\circledR}$ on the function of the isolated perfused dog kidney

\begin{tabular}{|c|c|c|c|}
\hline & Saline controls & $\begin{array}{l}\text { Trasylol } \\
500 \mathrm{U} / \mathrm{ml} \text { of blood }\end{array}$ & Paired comparison \\
\hline $\begin{array}{l}\text { Urine output } \\
\text { (ml/min } / \mathrm{g} \text { of kidney) }\end{array}$ & $\begin{array}{l}0.045 \pm 0.005 \\
(\mathrm{n}=11) \\
\end{array}$ & $\begin{array}{l}0.058 \pm 0.07 \\
(\mathrm{n}=11)\end{array}$ & $\begin{array}{l}0.013 \pm 0.002 \\
(p<0.01)\end{array}$ \\
\hline $\begin{array}{l}\text { Glomerular filtration } \\
\text { rate } \\
(\mathrm{ml} / \mathrm{min} / \mathrm{g} \text { of kidney) }\end{array}$ & $\begin{array}{l}0.40 \pm 0.02 \\
(\mathrm{n}=11)\end{array}$ & $\begin{array}{l}0.47 \pm 0.02 \\
(\mathrm{n}=10)\end{array}$ & $\begin{array}{l}+0.07 \pm 0.02 \\
(p<0.01)\end{array}$ \\
\hline $\begin{array}{l}\text { Renal blood flow } \\
(\mathrm{ml} / \mathrm{min} / \mathrm{g} \text { of kidney) }\end{array}$ & $\begin{array}{l}4.45 \pm 0.50 \\
(\mathrm{n}=11) \\
L\end{array}$ & $\begin{array}{l}4.69 \pm 0.38 \\
(\mathrm{n}=11) \\
\end{array}$ & $\begin{array}{l}+0.24 \pm 0.19 \\
\text { (N.S.) }\end{array}$ \\
\hline
\end{tabular}

${ }^{\text {a }}$ All results are expressed as mean \pm standard error of the mean $\quad$ N. S. = not statistically significant.

Table 2. Clearance rate of glucagon by the kidney at various glucagon or insulin concentrations

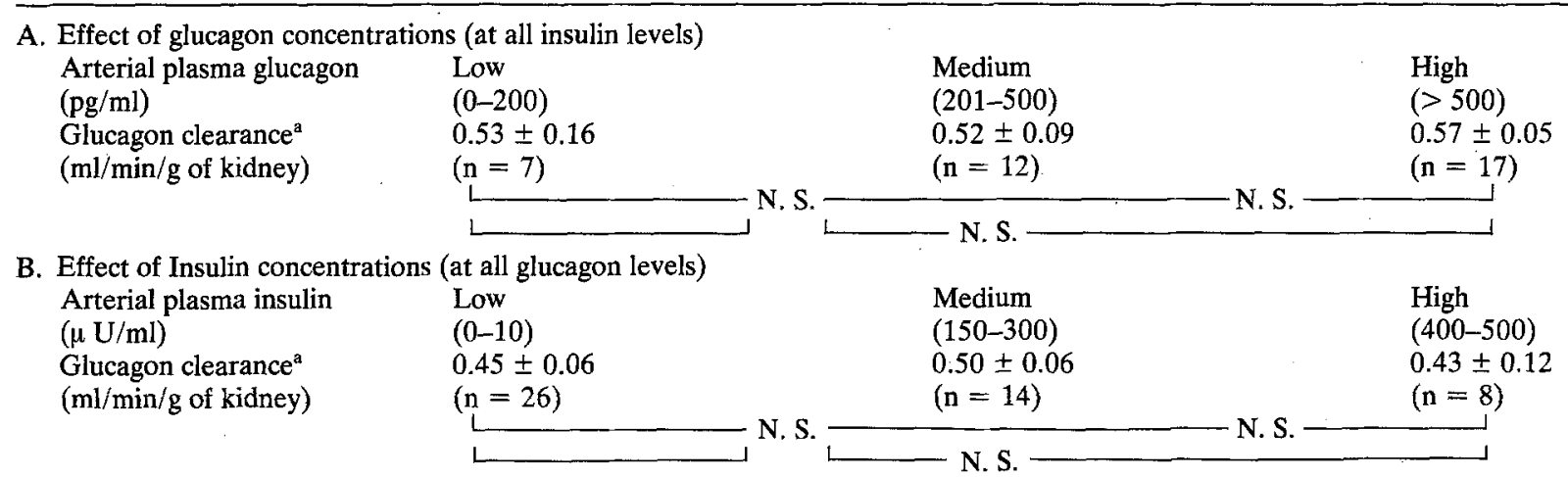

a Results are expressed as mean \pm SEM $\quad$ N. S. = not statistically significant

Table 3. Insulin uptake by the kidney at various glucagon concentrations ${ }^{\mathrm{a}}$

\begin{tabular}{|c|c|c|c|}
\hline $\begin{array}{l}\text { Arterial plasma glucagon } \\
(\mathrm{pg} / \mathrm{ml})\end{array}$ & $0-200$ & $201-800$ & $801-1600$ \\
\hline $\begin{array}{l}\text { Insulin uptake }{ }^{\mathrm{b}} \\
(\mu \mathrm{U} / \mathrm{min} / \mathrm{g} \text { of kidney })\end{array}$ & $\begin{array}{l}122.3 \pm 17.7 \\
(\mathrm{n}=9)\end{array}$ & $\begin{array}{l}138.1 \pm 7.5 \\
(n=17)\end{array}$ & $\begin{array}{l}119.5 \pm 15.9 \\
(\mathrm{n}=12)\end{array}$ \\
\hline
\end{tabular}

\footnotetext{
a Results are expressed as mean \pm standard error of the mean

${ }^{b}$ Mean arterial plasma insulin averaged $335.7 \pm 15.7 \mathrm{U} / \mathrm{ml}$; plasma insulin concentrations were similar in the 3 subgroups
}

entering the kidneys per minute $(r=0.952$ $\mathrm{p}<0.01)$. The mean renal clearance rate of glucagon, calculated on the basis of all the kidney glucagon uptake data, averaged $0.45 \pm 0.06 \mathrm{ml} / \mathrm{min} / \mathrm{g}$ of kidney $(n=26)$. The intercept of the regression line with the $X$ axis was found at about $100 \mathrm{pg} / \mathrm{ml}$ : statistical analysis, however, revealed that this point was not statistically different from zero. When kidney glucagon uptake was studied in the presence of insulin, insulin infusion resulted in reasonably stable arterial plasma insulin concentrations. Under these conditions, kidney glucagon uptake was again significantly correlated with both arterial plasma glucagon ( $\mathrm{r}=$ $0.913 ; p<0.01$ ) and the quantity of glucagon entering the kidneys per minute $(r=0.866 ; p<0.01)$. As indicated in Figure 1, the calculated regression lines were similar in the presence and in the absence of insulin. Statistical analysis revealed no significant dif- 
ference. The mean clearance rate of glucagon by the kidney during insulin infusion averaged $0.55 \pm 0.05$ $\mathrm{ml} / \mathrm{min} / \mathrm{g}(\mathrm{n}=36)$, a value which is not statistically different from the one obtained in the absence of insulin infusion. As indicated in Table 2, the clearance rate of glucagon by the kidney was similar at low, medium or high arterial plasma glucagon or insulin concentrations.

\section{Insulin Uptake by the Kidney at Various Arterial Concentrations of Glucagon}

As depicted in Table 3, for a mean arterial plasma insulin of $335.7 \pm 15.7 \mu \mathrm{U} / \mathrm{ml}(\mathrm{n}=41)$, kidney insulin uptake was of the same order of magnitude in the presence of varying arterial glucagon concentrations. None of the differences was statistically significant.

\section{Discussion}

As recently reviewed by one of us [6], the isolated dog kidney perfused with whole blood has been shown to be a physiologically valid model of the normal kidney. Since glucagon preservation in blood or plasma requires the presence of an anti-proteolytic agent [11] such as Trasylol ${ }^{\circledR}$, we investigated the possible effects this substance may have on kidney function. We demonstrated that the main parameters of kidney function were not (renal blood flow) or only slightly (urinary output, glomerular filtration rate) affected by Trasylol ${ }^{\circledR}$ included in the perfusion fluid. In previous experiments, renal handling of glucagon was investigated in dog kidneys acutely transplanted to the neck vessels of an anaesthetized dog. In this system [1], under basal conditions the clearance rate of glucagon averaged $0.482 \pm 0.063 \mathrm{ml} / \mathrm{min} / \mathrm{g}$ of kidney, a value very similar to the one found in the present experiments $(0.450 \pm 0.060 \mathrm{ml} / \mathrm{min} / \mathrm{g}$ of kidney). Kidney glucagon uptake averaged $89 \pm 14 \mathrm{pg} / \mathrm{min} / \mathrm{g}$ of kidney when the mean arterial plasma glucagon concentration averaged $193 \pm 14 \mathrm{pg} / \mathrm{ml}$. In the present investigation, kidney glucagon uptake averaged $90 \pm 20$ $\mathrm{pg} / \mathrm{min} / \mathrm{g}$ when arterial plasma glucagon values were selected to average $192 \pm 28 \mathrm{pg} / \mathrm{ml}(\mathrm{n}=8)$; thus in both systems, renal glucagon uptake was practically identical in the presence of similar arterial plasma glucagon concentrations. Renal blood flow in the isolated perfused dog kidney is slightly higher than that measured in situ or in the kidney transplanted to the neck [6]. This was also true in the present series: renal plasma flow was $2.30 \pm 0.22 \mathrm{ml} / \mathrm{min} / \mathrm{g}$ of kidney $(\mathrm{n}=$ 9) versus $1.53 \pm 0.07 \mathrm{ml} / \mathrm{min} / \mathrm{g}(\mathrm{n}=15)$ in our

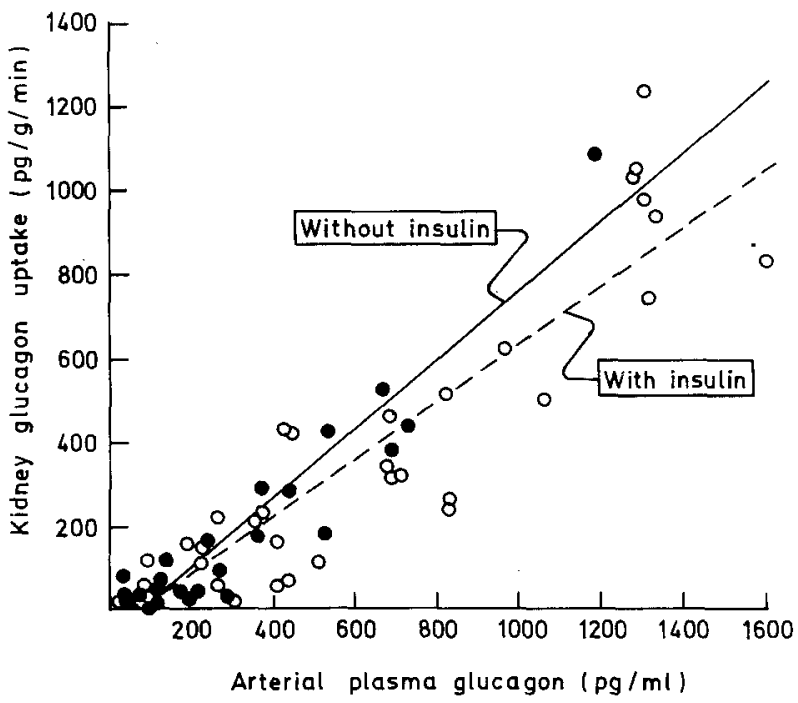

Fig. 1. Correlation between arterial plasma glucagon (A) and kidney glucagon uptake $(U)$ in the absence $(\bullet)$ and in the presence $(O)$ of insulin. $U$ equalled $0.686 \pm 0.046 \mathrm{~A}$ in the absence, and $0.622 \pm$ $0.032 \mathrm{~A}$ in the presence of insulin. At a $95 \%$ threshold, the confidence limits were $0.592-0.780$ in the absence, and $0.557-0.687$ in the presence of insulin

neck. The difference is statistically significant $(\mathrm{p}<$ 0.01 ). Since almost identical values of kidney glucagon uptake were obtained in the two systems, at similar arterial plasma glucagon concentrations but with different renal plasma flows (and, therefore, different quantities of glucagon entering the kidney per minute), one can conclude that kidney glucagon uptake is more dependant on arterial plasma glucagon concentration than on the quantity of glucagon entering the kidney per minute. In the kidneys transplanted to the neck system, urinary glucagon excretion accounted for less than 5 per cent of the total glucagon uptake [1]; this parameter was therefore not investigated in the present study. A surprising finding in our previous study was the apparent lack of correlation between arterial plasma glucagon concentration and kidney glucagon uptake [1]. However, in these experiments, glucagon concentrations were basal or were lowered by glucose infusion so that the range of arterial plasma glucagon concentrations studied was relatively narrow. Despite the lack of correlation, it was found that kidney glucagon uptake was, on the average, reduced by $50 \%$ when arterial plasma glucagon decreased from 193 to $136 \mathrm{pg} / \mathrm{ml}$. In the present study, measurements made when glucagon was at basal levels as well as when it was raised by exogenous glucagon infusion, allowed kidney glucagon uptake to be determined at arterial plasma glucagon concentrations ranging from 0 to $1600 \mathrm{pg} / \mathrm{ml}$ (a range covering most concentrations encountered in physiological or pathophysiological situations as well as those resulting experiments using the kidney transplanted to the 
from pharmacological stimulation of glucagon secretion [12]). Under these conditions, kidney glucagon uptake was significantly correlated with both arterial plasma glucagon or the quantity of glucagon entering the kidney per minute $(Q)$. On average, kidney glucagon uptake was $21.1 \pm 2.7$ per cent of $Q$. At low glucagon concentrations, i. e. below $125 \mathrm{pg} / \mathrm{ml}$, no glucagon uptake was usually detectable. This might suggest the existence of a threshold for glucagon clearance but, as indicated in the section on results, statistical analysis of our data do not permit us to draw any firm conclusion in this respect. As previously demonstrated [1], the urinary clearance of glucagon represents only a small percentage of the clearance of glucagon by the kidney. This observation is in agreement with earlier data which demonstrated that glucagon may be filtered through the glomerulus and reabsorbed at the tubular level [13]. This does not however exclude the possibility of a direct uptake from renal capillaries without previous filtration and reabsorption, as has been demonstrated for insulin [14-15]. The existence of such mechanism is supported by our finding that renal clearance rate of glucagon may be higher than the glomerular filtration rate. The intimate mechanism by which the kidney degrades glucagon remains unknown. In rat skeletal muscle, it has been demonstrated that insulin and glucagon can be degraded by the same enzyme; moreover it was shown that insulin was a competitive inhibitor of glucagon degradation $\left(\mathrm{Ki}=1.5 \times 10^{-8} \mathrm{M}\right)$ and that glucagon was a competitive inhibitor of insulin degradation $(\mathrm{Ki}$ $=5.3 \times 10^{-6} \mathrm{M}$ ). Since a similar enzyme was extracted from the kidney [16], we were interested in a possible interaction between glucagon and insulin uptake by the whole kidney. Our data clearly indicate that, over a wide range of arterial concentrations, glucagon uptake by the kidney was not significantly affected by the presence of insulin. This finding suggests that insulin and glucagon are handled independently by the kidney. This is consistent with the finding that, in rat kidney homogenates and at physiological hormonal concentrations, insulin degrading activity is located primarly in the cytosol, while glucagon degrading activity is found primarly in the $10^{5} \times \mathrm{g}$ pellet and is apparently associated with the brush border $[4,17]$. The cytosolic enzyme would correspond with the previously described "insulin specific protease" from muscle and could also degrade glucagon. The enzyme apparently associated with the brush border would be more specific for glucagon and would not metabolize insulin. Our data suggest that, under physiological conditions, the bulk of the renal glucagon degrading activity is carried out by mechanisms not affected by insulin. Further studies are needed to identify these mechanisms with the brush border associated neutral protease previously described by others [4, 17-19].

Acknowledgments. We thank Prof. F. Monfort for his help in the statistical analysis of our data. We are indebted to D. Binder and W. C. Duckworth for their help in the preparation of this manuscript. We acknowledge with thanks the skillful technical assistance of Mr. and Mrs. H. Thoumsin, A. Rombeaux, C. Cartenstadt, G. Lallemand and R. Lallemand. We are indebted also to E. Vaessen-Petit and H. MawetLavet for their secretarial assistance. This work was supported by the Fonds National de la Recherche Scientifique and the Fonds de la Recherche Scientifique Médicale of Belgium.

\section{References}

1. Lefebvre, P. J., Luyckx, A. S., Nizet, A. H.: Renal handling of endogenous glucagon in the dog: Comparison with insulin. Metabolism 23, 753--761 (1974)

2. Duckworth, W. C., Kitabchi, A. E.: Insulin and glucagon degradation by the same enzyme. Diabetes 23, 536-543 (1974)

3. Duckworth, W. C., Heinemann, M., Kitabchi, A. E.: Proteolytic degradation of insulin and glucagon. Biochim. biophys. Acta (Amst.) 377, 421-430 (1975)

4. Duckworth, W. C., Heinemann, M., Kemp, K.: Insulin (I) and glucagon (G) degradation by kidney. Clin. Res. 23, (Abstr.) 11 A (1975)

5. Cuypers, Y., Nizet, A., Baerten, A.: Technique pour la perfusion de reins de chien avec du sang hépariné. Arch. int. Physiol. Bioch. 72, 245-255 (1964)

6. Nizet, A.: The isolated perfused kidney: Possibilities, limitations and results. Kidney International 7, 1-11 (1975)

7. Huggett, A. S. G., Nixon, D. A.: Use of glucose-oxidase, peroxidase and o-dianisidine in determination of blood and urinary glucose. Lancet 1957 II, 368-370

8. Quabbe, H. J.: Modification der radioimmunologischen insulinbestimmung nach Hales und Randle. Diabetologia 5 , 101-107 (1969)

9. Luyckx, A. S.: Immunoassays for glucagon. In: Glucagon molecular physiology, clinical and therapeutic implications (eds. P. J. Lefebvre, R. H. Unger), pp. 285-298. Oxford: Pergamon Press 1972

10. Snedecor, G. W.: Statistical methods. 5th edition. Ames, Iowa: Iowa State University Press 1966

11. Eisentraut, A. M., Whissen, N., Unger, R. H.: Incubation damage in the radioimmunoassay for human plasma glucagon and its prevention with "Trasylol". Amer. J. med. Sci. 255, 137-142 (1968)

12. Unger, R. H., Lefebvre, P. J.: Glucagon physiology. In: Glucagon molecular physiology, clinical and therapeutic implications (eds. P. J. Lefebvre, R. H. Unger), pp. 213-244. Oxford: Pergamon Press 1972

13. Narahara, H. T., Everett, M. B., Simmons, B. S., Williams, R. H.: Metabolism of insulin- $\mathrm{I}^{131}$ and glucagon- $\mathrm{I}^{131}$ in the kidney of the rat. Amer. J. Physiol. 192, 227-231 (1958) 
14. Zaharko, D. S., Beck, L. V., Blankenbaker, R.: Role of the kidney in the disposal of radioiodinated insulin in dogs. Diabetes 15, 680-685 (1966)

15. Chamberlain, M. J., Stimmler, L.: The renal handling of insulin. J. clin. Invest. 46, 911-919 (1967)

16. Kitabchi, A. E., Stenz, F. B., Bobal, M. A.; Degradation of insulin and proinsulin by various organ homogenates of rat. Diabetes 21, 1091-1101 (1972)

17. Duckworth, W. C.: Insulin and glucagon degradation by the kidney. Biochim. biophys. Acta (Amst.), (in press 1976)

18. George, S. G., Kenny, A. J.: Studies on the enzymology of purified preparation of brush border from rabbit kidney. Biochem. J. 134, 43-57 (1973)
19. Kerr, M. A., Kenny, A. J.: The molecular weight and properties of a neutral metallo-endopeptidase from rabbit kidney brush border. Biochem. J. 137, 489-495 (1974)

Received: January 29, 1976, and in revised form: May 20, 1976

Dr. P. J. Lefebvre

Institut de Médecine

Hôpital de Bavière

$66 \mathrm{Blv}$, de la Constitution

B-4020 Liège

Belgium 